\title{
Alcohol Toolkit: Empowering Sabah Indigenous Communities to Reduce Alcohol- Related Harm
}

Helen Benedict Lasimbang ${ }^{1 *}$, Liz Eckermann², Wendy Shoesmith ${ }^{1}$, Sandi James ${ }^{3}$, Aisat Ellik bin Igau @ Oswald Iggau $^{4}$, Lee Kuok Tiung ${ }^{5}$, Jephte Sompud ${ }^{6}$, Asong Joseph ${ }^{1}$

${ }^{1}$ Faculty of Medicine and Health Sciences, Universiti Malaysia Sabah,

Kota Kinabalu, Sabah, Malaysia

2 School of Humanities and Social Sciences, Deakin University of Australia

${ }^{3}$ Faculty of Health, Science and Engineering, La Trobe University, Victoria, Australia

${ }^{4}$ Faculty of Business, Economics and Accountancy, Universiti Malaysia Sabah, Kota Kinabalu, Sabah, Malaysia

${ }^{5}$ Faculty of Humanities, Arts and Heritage, Universiti Malaysia Sabah,

Kota Kinabalu, Sabah, Malaysia

${ }^{6}$ Faculty of Science and Natural Resources, Universiti Malaysia Sabah, Kota Kinabalu, Sabah, Malaysia

*Corresponding author's email: hbl66@ums.edu.my

Received: 8 November 2018

Accepted: 10 July 2019

Keywords:

alcohol toolkit, empowering

communities, Sabah, alcohol harm,

focus group discussion

\section{ABSTRACT}

Alcohol misuse compromises the quality of life of individuals, families, communities and whole societies in a variety of ways. Malaysia acknowledges the problems, implementing policies and health promotion activities in line with the World Health Organization Global Strategy to reduce the harmful use of alcohol by $10 \%$ between 2010 and 2025 . Sabah, one of two Malaysian states on the island of Borneo, has more than $\mathbf{3 0}$ different indigenous ethnic groups. Alcohol production and consumption have traditional and unique roles in the cultural practices of many of these groups, making one common programme difficult to implement. Preliminary research suggests that alcohol is a serious problem in indigenous communities in Sabah. It also shows lack of knowledge on recommended limits for alcohol consumption and understanding of alcohol-related harm. The objective of this action-research is to produce a toolkit that will transfer knowledge and empower communities to adopt safer drinking and reduce alcohol-related harm. It must be attractive, appropriate, easily understood and be able to be tailored to suit different communities. The alcohol tool-kit was developed by a group of academicians using evidence-based information. Qualitative research methods were used to evaluate the initial alcohol tool-kit. A purposive sample of $\mathbf{4 5}$ village representatives was selected and divided into $\mathbf{5}$ groups for focus group discussion. Their feedback was recorded and transcribed verbatim. The alcohol tool-kit was edited accordingly. All participants agreed the alcohol tool-kit was important and can empower communities to reduce alcohol-related harm directly improving their quality of life. The amended alcohol toolkit will be recommended for health promotion material and evaluated from time to time. 


\section{INTRODUCTION}

The harmful use of alcohol causes significant burden to individuals, families and societies ${ }^{1}$. According to the WHO fact sheet on alcohol, in 2015 the harmful use of alcohol directly or indirectly caused 3.3 million deaths. This represents around $5.9 \%$ of all deaths worldwide every year. It is also reported to be the cause of more than 200 diseases and injury conditions ${ }^{2}$. Apart from the health consequences, excessive use of alcohol has been shown to result in social and economic consequences $^{3}$. The consequences of alcohol consumption depend on the volume consumed, pattern of drinking and the quality or type of alcohol being consumed ${ }^{4}$. There are wide and varied reasons for why people consume alcohol. It has been used for centuries in these cultures for spiritual purposes and celebrations, as well as for relaxation and socialization ${ }^{5}$.

The population of Malaysia is about 30 million, of which $61.3 \%$ are Muslim ${ }^{6}$. Alcohol consumption is prohibited in Islam ${ }^{7}$ which may explain the low prevalence of $7.7 \%$ of alcohol consumption reported in this country 8 . The highest prevalence occurs in Kuala Lumpur, followed by Sarawak and Sabah"8, 9 . Sarawak and Sabah are Malaysian states located in East Malaysia, on the island of Borneo. They differ from the states located in West Malaysia because the population is mostly comprised of large indigenous communities where alcohol plays an important role in their cultural traditions ${ }^{10}$. Although the overall prevalence of alcohol consumption in Sabah and Sarawak is low ${ }^{11}$, it has been reported that $50 \%$ of those who consume alcohol drink in ways considered to be harmful ${ }^{11}$. Mutalip et al. (2014) ${ }^{11}$ also reported that among those who drink, $23.6 \%$ drink in risky ways. Highrisk drinking was noted to be more prevalent among rural drinkers, indigenous peoples of Sabah and Sarawak, low education and low income households ${ }^{11}$. In Sabah, locally brewed (unrecorded) alcohol such as montoku, tapai, and smuggled alcohol are cheaply available
12. Research on alcohol in this region is scarce, preventing an accurate picture of the magnitude of alcohol-related harm in Sabah. However, it is common to read reports in newspapers about alcohol-related harm such as domestic violence, motor-vehicle accidents, and fights ${ }^{10}$. It is noted that alcohol plays a significant role in many presentations to the psychiatric hospital in Sabah. Alcohol is also a contributing factor in relapse of mental illness in some individuals. The government of Malaysia acknowledges the problems related to alcohol use and has introduced various strategies to address this issue $^{13}$. In 1976 the Malaysian Government introduced drink driving laws and penalties. In 1979 the excise act was implemented, and in 2010 they included abstaining from alcohol as part of a healthy lifestyle campaign ${ }^{14}$. A national action plan (2013 - 2020) was also created with the intention to prevent and reduce alcoholrelated harm ${ }^{15}$.

The serious burden of alcohol to individuals and communities in most countries has made it an international issue. In 2010, during the 63rd World Health Assembly, the harmful use of alcohol worldwide was one of the four public health issues discussed. This assembly also endorsed the global strategy to reduce the harmful use of alcohol ${ }^{4}$. The strategy includes extensive and detailed evidencebased guides for global, regional, national and community-based interventions ${ }^{4}$. The outcomes of the various strategies to reduce alcohol related harms are unique depending on the local context ${ }^{16,17,18}$. It is suggested that community-based and bottom-up prevention measures are the most effective strategies to reduce drinking and alcohol related problems $^{19,20,21,22}$.

In Sabah, the large number of different ethnic groups makes one single programme difficult to implement. Strategies that are appropriate and work in one population may not be appropriate for another population. There is a need for a tailored strategy that is appropriate and acceptable for multi-ethnic 
communities; one that is accepting of local cultural traditions; and meets communities and individuals where they currently are in terms of understanding and desire for change. The limitations of abstinence-based approaches where individuals and communities are not interested in abstinence can be addressed where communities are interested in reducing the problems caused by alcohol ${ }^{23,24}$. Alcohol harm reduction has been shown to be an effective approach when it is part of a comprehensive policy package, addressing all levels of policy and practice and considering the communities needs and wishes ${ }^{25}$. Top down approaches, where the communities are not involved and government policies are made without consideration of the local context, appear to have little effect in rural and remote communities ${ }^{26}$.

The overall objective of this project was to produce a community-inclusive tool-kit that will transfer knowledge and empower communities to adopt safer drinking and reduce alcohol-related harm.

\section{MATERIALS AND METHODS}

This action-research was divided into two phases from February 2016 to August 2017. The first phase of the project was the development of the 'alcohol intervention tool-kit' using available evidence-based data ${ }^{4,26,27}$. A tool-kit tailored for the indigenous communities of
Sabah was developed by a team comprising of local NGOs and academicians in early $2009^{10}$. This initial 'alcohol intervention tool-kit' was given to several indigenous communities and they reported it was somewhat useful in reducing alcohol-related harm. However, this initial 'tool-kit' was not formally reviewed nor adapted to suit the individual communities. It was considered alongside other data, programmes and activities already existing in Sabah. This information was then collated into booklets, each booklet addressing a different topic related to alcohol harm reduction. Collectively it was called 'alcohol tool-kit' (Figure 1). The final alcohol tool-kit was one introductory pamphlet and a set of 7 booklets (Table 1). Bahasa Malaysia was used for the booklets because more than $90 \%$ of the target population can read and speak this language ${ }^{28}$.
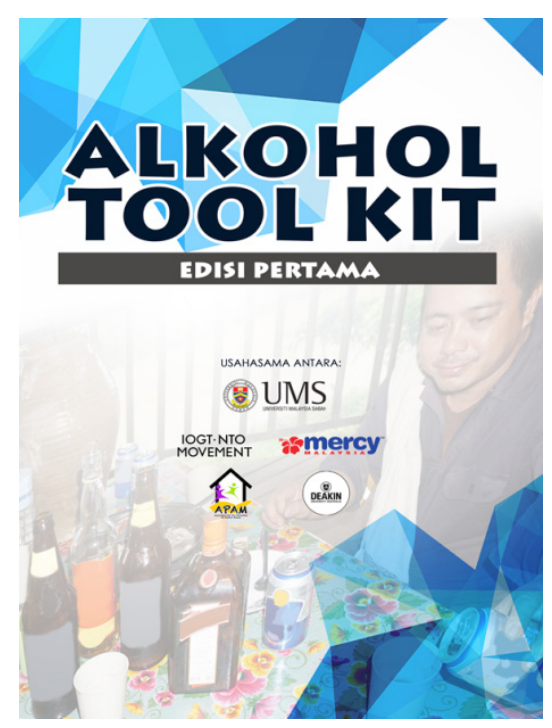

Figure 1 Alcohol toolkit

Table 1 Content of the alcohol tool-kit

\begin{tabular}{|l|l|}
\hline Number & \multicolumn{1}{|c|}{ Content } \\
\hline 1 & Introduction to alcohol tool-kit \\
2 & Topic 1: Making choices to drink or not to drink? \\
3 & Topic 2: You and alcohol \\
4 & Topic 3: General knowledge about alcohol \\
6 & Topic 4: Alcohol and culture \\
7 & Topic 5: Reducing alcohol-related harm \\
8 & Topic 6: A guide to changing your drinking habits \\
\hline
\end{tabular}


The second phase was the evaluation of the 'Alcohol Tool-kit'. A qualitative research method was used, and the data was collected with thematic interview to evaluate the attractiveness, appropriateness, and understanding of the alcohol tool-kit. These indicators were selected through discussion to ensure the tool-kit had the best possible chance of uptake in the target communities. Purposive sampling was used to achieve maximal variation, with participants selected from various backgrounds in terms of age, occupation, gender and position in the village. A one-day workshop was organized for phase 2 to ensure that ample time was given to discuss in detail the various aspects of the tool-kit. At the beginning of the workshop, all participants were given an introductory talk on the toolkit and the objectives of the workshop.

The participants were encouraged to join the group they were comfortable with. There were 5 groups with 9 participants in each group. This was to ensure the opportunity for varied inputs from all participants. The facilitators were academicians and trained members of the community. The summary of participants' socio-demographic profiles is shown in Table 2.

Table 2 Socio-demographic of participants who participated in the Alcohol Tool-kit evaluation

\begin{tabular}{|c|c|c|}
\hline Demography & $N=44$ & $\%$ \\
\hline $\begin{array}{ll}\text { Gender } & \\
& \text { Male } \\
& \text { Female }\end{array}$ & $\begin{array}{l}19 \\
25\end{array}$ & $\begin{array}{l}43.2 \\
56.8\end{array}$ \\
\hline $\begin{array}{l}19-30 \\
31-40 \\
41-50 \\
51-60\end{array}$ & $\begin{array}{c}5 \\
8 \\
17 \\
14\end{array}$ & $\begin{array}{l}11.4 \\
18.2 \\
38.6 \\
31.8\end{array}$ \\
\hline $\begin{array}{ll}\text { Religion } & \\
& \text { Christian } \\
& \text { Muslim }\end{array}$ & $\begin{array}{c}42 \\
2\end{array}$ & $\begin{array}{c}95.5 \\
4.5\end{array}$ \\
\hline Kadazandusun & 44 & 100 \\
\hline $\begin{array}{l}\text { Occupation } \\
\qquad \begin{array}{l}\text { Farmer } \\
\text { Housewife } \\
\text { JKKK } \\
\text { Teacher } \\
\text { Clerk } \\
\text { Retired } \\
\text { Not stated }\end{array}\end{array}$ & $\begin{array}{c}15 \\
3 \\
7 \\
1 \\
1 \\
1 \\
16\end{array}$ & $\begin{array}{c}34.1 \\
6.8 \\
15.9 \\
2.3 \\
2.3 \\
2.3 \\
36.4\end{array}$ \\
\hline
\end{tabular}

The briefing and interview guide was given to the facilitators to ensure uniformity of the discussion. Participants discussed, commented and gave suggestions based on attractiveness, appropriateness, the ease of readability and understanding, so the booklets would be more effective for the community. Notes and a summary of their answers were recorded and presented to all participants by one selected member from each group. This enabled the other groups to give further input or debate issues of conflict.
The community input was documented and summarized. Inductive content analysis was completed using Atlas.ti7. The feedback and input were incorporated in the final version of the alcohol toolkit. Ethical permission was taken [JKEtika1/16(2)].

\section{RESULTS}

All participants acknowledged that alcoholrelated harm is a problem in their village. During the workshop, participants agreed that 
the information in the toolkit was relevant and important. They agreed that it would be helpful in encouraging and supporting the communities to reduce alcohol-related harm. The community input was summarized into four main themes.

\section{Attractiveness}

Participants from all five groups commented that the covers of the toolkits were dull and boring. They suggested adding pictures, colours and improving the paper quality of the cover. All participants proposed to include more pictures and increase the font size. They also suggested that using real pictures of local communities would make the toolkit more attractive and relevant.

\section{Appropriateness}

All groups commented that illustrations depicting foreigners in the tool-kit was inappropriate. They suggested to pictures of local people would be more appropriate. Two of the groups expressed that they did not appreciate seeing a picture of a drunken dog in the booklet and wanted it to be removed. They stated that they considered it humiliating and not an appropriate way to illustrate the point at hand. One group suggested that the standard alcohol unit be stated in Kadazandusun as well as Malay. Another group suggested that the toolkit on 'Making a choice: Should I drink alcohol or not?' should be the first booklet in the toolkit rather than the fourth. This booklet is aimed towards adolescents that have not yet started drinking. The goal is to help empower them to make healthy choices regarding the use of alcohol. Two of the groups felt that cartoons depicted playfulness and were not appropriate for certain sections due to the seriousness of the topic. They stated they would prefer the illustration dialogue to be constructive and serious and avoid sarcasm or humour.
Ease of Readability and Understanding All the participants agreed that the content of the toolkit is simple, clear and informative. The language is easy to understand and accessible and useful for people of all ages. They found some words difficult to understand; such as "piawai" (standard), "akut" (acute) and "toolkit". Two out of five groups stated that it is not necessary to repeat 'one standard alcohol drink' in all booklets in the toolkit. These concerns were discussed. This concept is new to these communities and is considered important for reducing alcohol-related harm. The working group agreed that 'one standard alcohol drink' is an integral component of the educational side of the booklets and that it is an important concept that needs to be repeated. To place this into a local context was also noted an important path to it being taken up by the communities.

\section{Additional Comments to Make the Toolkit More Effective}

The leaders (or heads) of the villages suggested to include information about native customary law. A section in Kadazandusun native law provides information for community and community leader responses and consequences for negative behaviour due to alcohol intoxication. It was also suggested to add a table of contents and acknowledgements.

\section{DISCUSSION}

The communities welcomed the team openly and with enthusiasm. Possible reasons this occurred so readily include: the team had involved the communities in the discussions and development of the tool-kit; the team did not enter the community to impart knowledge onto the people, but rather as seekers of knowledge and collaborators in the process; *the team asked the community for their assistance to develop a toolkit that would address their needs, rather than stating a problem and giving directions on what 
needed to be changed; participants were respected as holders of the knowledge on what was needed and which intervention strategies might work within their community. They had acknowledged that alcohol was causing problems in their society and were seeking ways to solve it.

Participants were drawn from various backgrounds, educational levels, and occupations, as well as positions within the community. No difficulties were reported from any of the participants related to understanding the information in the toolkit. Literacy problems were overcome by reading the material in a group. Discussion of the toolkit contents along with the illustrations and tables enabled sufficient access to the material by all participants. The participants were very cooperative, actively involved and remained for the duration of the workshop. The importance of community participation and input was demonstrated in this workshop. This was to ensure the communities were an active part of the tool-kit development and claimed some ownership over its development ${ }^{28}$.

Participants spoke about how some of the information and illustrations in the toolkit were not acceptable for their community, despite being thought to be appropriate by the academic team. For example, people felt that the cartoons portrayed playfulness and minimized the seriousness of the subject. They felt it was more suitable for the booklet aimed at young people. Participants stated that the use of images of foreigners in the illustrations seemed inconsistent with the aim of the ToolKit. The academic team had considered this point prior to the workshop but decided to include those images due to lack of access to alternative images.

During the workshop, participants were involved to address alcohol issues in the communities. This enabled them to feel heard, respected and motivated to participate actively in reducing alcohol-related harm. Participants also learned and gained knowledge about alcohol while reviewing the alcohol toolkit. This increase of knowledge also allows "word of mouth" communication of the importance of alcohol harm reduction, enables communities to identify problems and difficulties and feel confident in beginning to tackle these issues.

The academic team was not previously aware of the importance of including native customary law in the toolkit. People knowledgeable in this area were subsequently consulted and customary law then included in the alcohol tool-kit booklets. Tailoring a programme or intervention to be culturally appropriate and relevant for the populations can make it more effective ${ }^{29,30}$. The WHO global strategy to reduce alcohol-related harm has recommended community involvement and engagement as an important strategy. This project initially started with academics developing the toolkit without the communities' feedback or input. Involving the community in the further development of the toolkit increased the acceptance of this intervention. It gave the communities a sense of ownership and increased its implementation and availability.

\section{Challenges in Tailoring the 'Alcohol Tool-kit'}

As noted above, some participants were illiterate which made accessing the materials difficult. The team needs to further consider appropriate methods that could overcome this barrier once the toolkit is distributed into the communities. To be an effective strategy in the communities, the toolkit needs to be printed in sufficient quantity to be distributed at all appropriate venues.

Currently, the alcohol toolkit is limited to literate persons. Further evaluation of the effectiveness of the toolkit is required once it is distributed. This will require additional funding. Plans on how to gather data on the uptake of the toolkit and methods for assessing the effectiveness will need to be 
considered. The alcohol toolkit is not a selfhelp book. It has been developed to provide education and awareness to individuals and communities. Toolkit 7 can function as a selfhelp tool although it also may require some guidance in application.

\section{CONCLUSION}

Addressing alcohol-related harm is an ongoing process. It is a challenge for health professionals across the globe, particularly when working with more isolated, lower socioeconomic and less educated communities. It is even more challenging in communities where alcohol is a strong aspect of cultural practices. Simply developing and distributing the toolkit amongst the communities is not enough. There is a need for ongoing engagement and collaboration to assist with the uptake of this message and to ensure appropriate and effective utilization of the tools. Further programmes need to be implemented to develop the support and intervention opportunities available in these areas.

\section{ACKNOWLEDGEMENTS}

District Officer of Tambunan Mr Thomas Logijin, Members of Intervention Group of Alcohol Misuse (IGAM) MERCY Malaysia, IOGTNTO Sweden and KTP (Knowledge Transfer Program) Grant from Fifth Rolling Plan, phase 2 Reference number:FK-MHC/1(UMS-15). Village heads and communities of Mukim Nambayan, Tambunan who has attended and participated in this programme.

\section{CONFLICT OF INTEREST}

The authors declare that they have no competing interests in publishing this article.

\section{REFERENCES}

1. World Health Organisation. (2014). Global status report on alcohol and health 2014. Global Status Report on Alcohol 1 - 392. https://doi.org//entity/substance_abuse/ publications/global_alcohol_report/en/ index.html

2. Shield KD, Parry C, Rehm J. (2013). Chronic diseases and conditions related to alcohol use. Alcohol Research: Current Reviews 35 (2): 155 - 173. https://doi.org/1512625192

4. World Health Organization. (2010). Global strategy to reduce the harmful use of alcohol. World Health Organization 44. Retrieved from www.who.int/substance_abuse

3. World Health Organization. (2015). Global strategy to reduce the harmful use of alcohol. World Health Organization 44. Retrieved from https://www.who.int/topics/ noncommunicable_diseases/factsheets/en/.

5. Amit N, Hasking P, Manderson L. (2013). Demographic factors associated with alcohol use among young men in rural areas of Sarawak. Addiction Research \& Theory 21 (5): 391 - 401. https://doi.org/10.3109/1606 6359.2012 .731114 .

6. Department of Statistics Malaysia. (2015). Department of Statistics Malaysia Official Portal. Department of Statistics, Malaysia, (November), 1 - 5. https://doi.org/201608-11.

7. Michalak L, Trocki K. (2006). Alcohol and Islam: An overview. Contemp. Drug Probs 27 (2): 523 - 563. Retrieved from http://heinonlinebackup.com/hol-cgibin/get_pdf.cgi?handle=hein.journals/ condp33\&section $=32$

8. NHMS. (2011). National Health and Morbidity Survey 2011. Ministry of Health (Vol. 2). https://doi.org/10.1017/ CBO9781107415324.004

9. National and Health and Morbidity survey (2015): Non-communicable diseases, risk factors and other health problems. Ministry of Health of Malaysia (Vol. II).

10. Lasimbang HB, Shoesmith W, Mohd Daud MNB et al. (2015). Private troubles to public issue: Empowering communities to reduce alcohol-related harm in Sabah, Malaysia. Health Promotion International dav090. https://doi.org/10.1093/heapro/dav090. 
11. Mutalip MHBA, Kamarudin RB, Manickam M et al. (2014). Alcohol consumption and risky drinking patterns in Malaysia: Findings from NHMS 2011. Alcohol and Alcoholism 49 (5): 593 - 599. https://doi.org/10.1093/alcalc/ agu042

12. Shoesmith WD, Oo Tha N, Naing KS et al. (2016). Unrecorded alcohol and alcoholrelated harm in rural Sabah, Malaysia: A socio-economically deprived region with expensive beer and cheap local spirits. Alcohol and Alcoholism 51 (6): 741 - 746. https://doi.org/10.1093/alcalc/agw005.

13. He W. (2011). Management of substance abuse - Malaysia Profile 2011. World Health Organization 2011.

14. Ministry of Health. (2010). Annual Report: Noncommunicable Disease (NCD) Section $1-64$.

15. Kementerian Kesihatan Malaysia. (2014). Pelan Tindakan Kebangsaan: Pencegahan dan pengurangan kemudaratan alkohol 2013 - 2020 (PeTA 2013 - 2020) (First, Vol. 1). Putrajaya: Author.

16. World Health Organization. (2008). Global health adds life to years. Geneva: World Health Organisation.

17. World Health Organization. (2011). Global health adds life to years. Geneva, World Health Organisation.

18. Babor TF, Higgins-Biddle JC. Saunders, J. B, Monteiro M. G. (2001). AUDIT: The alcohol use disorders identification test: Guidelines for use in primary health care. 2nd edition. Substance Abuse Department, World Health Organization. pp. 1 - 38.

19. Perry $\mathrm{CL}$, Williams $\mathrm{CL}$, Veblen-Mortenson $\mathrm{S}$ et al. (1996). Project Northland: Outcomes of a community-wide alcohol use prevention program during early adolescence. American Journal of Public Health 86: 956 - 965.

20. Holder HD, Gruenewald PJ, Ponicki WR. (2000). Effect of community-based interventions on high-risk drinking and alcohol-related injuries. Journal of the American Medical Association 284 (18): 2341 - 2347.

21. Wagenaar AC, Murray DM, Toomey TL. (2000). Communities mobilizing for change on alcohol (CMCA): Effects of a randomized trial on arrests and traffic crashes. Addiction 95 (2): $209-217$.
22. Midford R., Wayte K, Catalano P et al. (2005) The legacy of a community mobilisation project to reduce alcohol-related harm. Drug and Alcohol Review 24: 3 - 11.

23. Marlatt GA, Witkiewitz K. (2002). Harm reduction approaches to alcohol use. Addictive Behaviors 27 (6): 867 - 886. https:// doi.org/10.1016/S0306-4603(02)00294-0.

24. Dougherty DM, Lake SL, Hill-Kapturczak N et al. (2015). Using contingency management procedures to reduce at-risk drinking in heavy drinkers. Alcoholism: Clinical and Experimental Research 39 (4): 743 - 751. https://doi.org/10.1111/acer.12687.

25. Logan DE, Marlatt GA. (2010). Harm reduction therapy: A practice-friendly review of research. Journal of Clinical Psychology 66 (4): 201 - 214. https://doi.org/10.1002/jclp.

26. ToolBox C. (2013). Community Tool BoxChapter 5. Choosing Strategies to Promote Community Health and Development. Section 5. Coalition Building I: Starting a Coalition. Retrieved from http://ctb. ku.edu/en/table-of-contents/assessment/ promotion-strategies/start-a-coaltion/main.

27. Babor T, Caerano R, Casswell S et al. (2010). Alcohol: No ordinary commodity research and public policy. New York: Oxford University Press Inc.

28. Omar A. (2009). Pemberdayaan bahasa Melayu sebagai perekat bangsa Malaysia. Kongres Internasional Masyarakat Linguistik Indonesia (KIMLI), Batu, Malang, Jawa Timur. 5 - 7 November 2009.

29. Kelly CM, BakerEA, Brownson RC, Schootman, M. (2007). Translating research into practice: Using concept mapping to determine locally relevant intervention strategies to increase physical activity. Evaluation and Program Planning 30 (3): 282 - 293.

30. Kreuter MW, Skinner CS, Holt CL et al. (2005). Cultural tailoring for mammography and fruit and vegetable intake among lowincome African American women in urban public health centers. Preventive Medicine 41 (3): $53-62$. 